\title{
Application of the Transmission Line Matrix method for outdoor sound propagation modelling - Part 2: Experimental validation using meteorological data derived from the meso-scale model Meso-NH
}

\author{
Pierre Aumond ${ }^{\mathrm{a}}$, Gwenaël Guillaume ${ }^{\mathrm{a}}$, Benoit Gauvreau ${ }^{\mathrm{a}}$, Christine Lac ${ }^{\mathrm{b}}$, \\ Valery Masson ${ }^{\mathrm{b}}$, Michel Bérengier ${ }^{\mathrm{a}}$ \\ ${ }^{a}$ Institut Français des Sciences et Technologies des Transports, de l'Aménagement et des \\ Réseaux, Département Infrastructures et Mobilité, Route de Bouaye, B.P. CS4, 44344 \\ Bouguenais Cedex, France \\ ${ }^{b} 42$ avenue Gaspard Coriolis, 31100 Toulouse
}

\begin{abstract}
Outdoor sound prediction is both a societal concern and a scientific issue. This paper deals with numerical simulations of micrometeorological (temperature and wind) fields for environmental acoustics. These simulations are carried out using the reference meso-scale meteorological model at the Meteo-France weather agency (Meso-NH). Meso-NH predictions at very fine scales (up to $3 \mathrm{~m}$ ), including new developments (drag force approach), are validated both numerically and experimentally under stable, unstable and neutral conditions. Then, this information can be used as input data for the acoustic propagation model. The time-domain acoustic model is based on the Transmission Line Matrix method. Its development has also been promoted for application to outdoor sound propagation, i.e. to take into account topography, ground impedance, meteorological conditions, etc. In
\end{abstract}

Email address: gwenael.guillaume@ifsttar.fr (Gwenaël Guillaume) 
Part 1, the presentation and evaluation of the Transmission Line Matrix method showed the relevance of this method's use in the context of environmental acoustics. Finally, simulated noise levels under different propagation conditions were compared to in-situ measurements. Satisfactory results were obtained regarding the variability of the observed phenomena.

Keywords:

Meso-NH, Transmission Line Matrix model, Time-Domain method, Outdoor sound propagation, Micrometeorology, Experimental data

\section{Introduction}

Regarding environmental acoustics, outdoor sound prediction is both a societal concern and a scientific issue. It is now considered that as of $50 \mathrm{~m}$ from the sound source, the meteorological effects on sound propagation must be taken into account [1]. In order to qualify and quantify this influence, many acoustical propagation models have been developed. The meteorological information is introduced through an atmospheric model of differing complexity (from the simple linear vertical profile of wind and temperature to a complex representation of the atmospheric boundary layer). In order to obtain such a complex representation of the boundary layer, the purpose of this paper is to use simulation results of the meso-scale meteorological model Meso-NH in Large-Eddy Simulation (LES) configurations. Then, this information can be used as input data for the time-domain sound propagation model: The Transmission Line Matrix (TLM) method. The associated paper (Part 1) deals with the presentation and evaluation of the Transmission Line Matrix method in the context of environmental acoustics. In this paper 
(Part 2), the two different models (acoustical and meteorological) are compared with experimental data derived from the Lannemezan-2005 campaign.

In Section 2, the experimental campaign of Lannemezan-2005 is first presented. An overview of the meso-scale meteorological model Meso-NH and its configuration is given in Section 3. The results obtained by this model over the Lannemezan site are next compared with the meteorological measurements during the experimental campaign. In Section 4, the numerical results of the TLM simulations using Meso-NH simulated meteorological fields as input data are shown and discussed.

\section{Experimental campaign: Lannemezan 2005}

Lannemezan-2005 was an experiment conducted near the city of Lannemezan (France) by the Laboratoire Central des Ponts et Chaussées (exLCPC, now Ifsttar), Electricité De France (EDF), Société Nationale des Chemins de Fer (SNCF) and École Centrale de Lyon (ECL) [1]. It was designed to be a three-month experiment (from June until August 2005) in order to study meteorological and ground effects on outdoor acoustic propagation. Fig. 1 shows the Lannemezan-2005 site, its topography and the location of a selected set of sensors. The Lannemezan-2005 site is flat and covered with prairie grass. There are tree barriers around $10 \mathrm{~m}$ high on each side of the domain studied. The sound level of a broad-band omnidirectional sound source had been measured throughout the duration of the campaign by a cluster of microphones following 3 propagation directions: PD1, PD2, PD3 (and PD4, not considered in this paper because of the non flat ground). In addition to microphones, a large number of meteorological sensors were 
deployed in this area. For the meteorological part of the study, a 3D ultrasonic anemometer and two $10 \mathrm{~m}$ high fully-equipped meteorological towers (wind speed, wind direction and temperature at heights of $1 \mathrm{~m}, 3 \mathrm{~m}$ and $10 \mathrm{~m}$ ) were placed respectively at 75,125 and $175 \mathrm{~m}$ from the source in each direction. Moreover, a $60 \mathrm{~m}$ high meteorological tower with three 3D ultrasonic anemometers, 3 temperature sensors and 3 humidity sensors was located $200 \mathrm{~m}$ north of the source. Information about turbulence kinetic energy was given by the 3D ultrasonic anemometers and one $60 \mathrm{~m}$ mast with a sampling rate of $10 \mathrm{~Hz}$ averaged over 10 minutes. The meteorological towers provided temperature and wind measurements every 10 seconds, averaged over 15 minute samples. Regarding noise measurements integrated on $1 \mathrm{~s}$ duration $\left(\mathrm{Leq}_{1 \mathrm{~s}}\right.$ for each $1 / 3$ octave bands on $\left.[100 \mathrm{~Hz} ; 5 \mathrm{kHz}]\right)$, the different microphones were located 50, 100 and $150 \mathrm{~m}$ from the sound source in the different propagation directions. More details are given in Ref. [1].

In order to validate the meteorological model, 3 typical clear-sky conditions were chosen in the Lannemezan-2005 experimental database. As presented by Foken [2], the dimensionless stability parameter $\zeta\left(\zeta=z / \mathrm{L}_{\mathrm{MO}}\right.$, where $z$ is the height above ground and $\mathrm{L}_{\mathrm{MO}}$ stands for the Monin-Obukhov length [2]) has been used to define the degree of stratification of the surface layer (unstable, neutral and stable atmospheres correspond respectively to $-1<\zeta,-1<\zeta<0$ and $0<\zeta)$. These parameter values have been calculated from averaged measurements (15 min) of the 3D ultrasonic anemometers. 

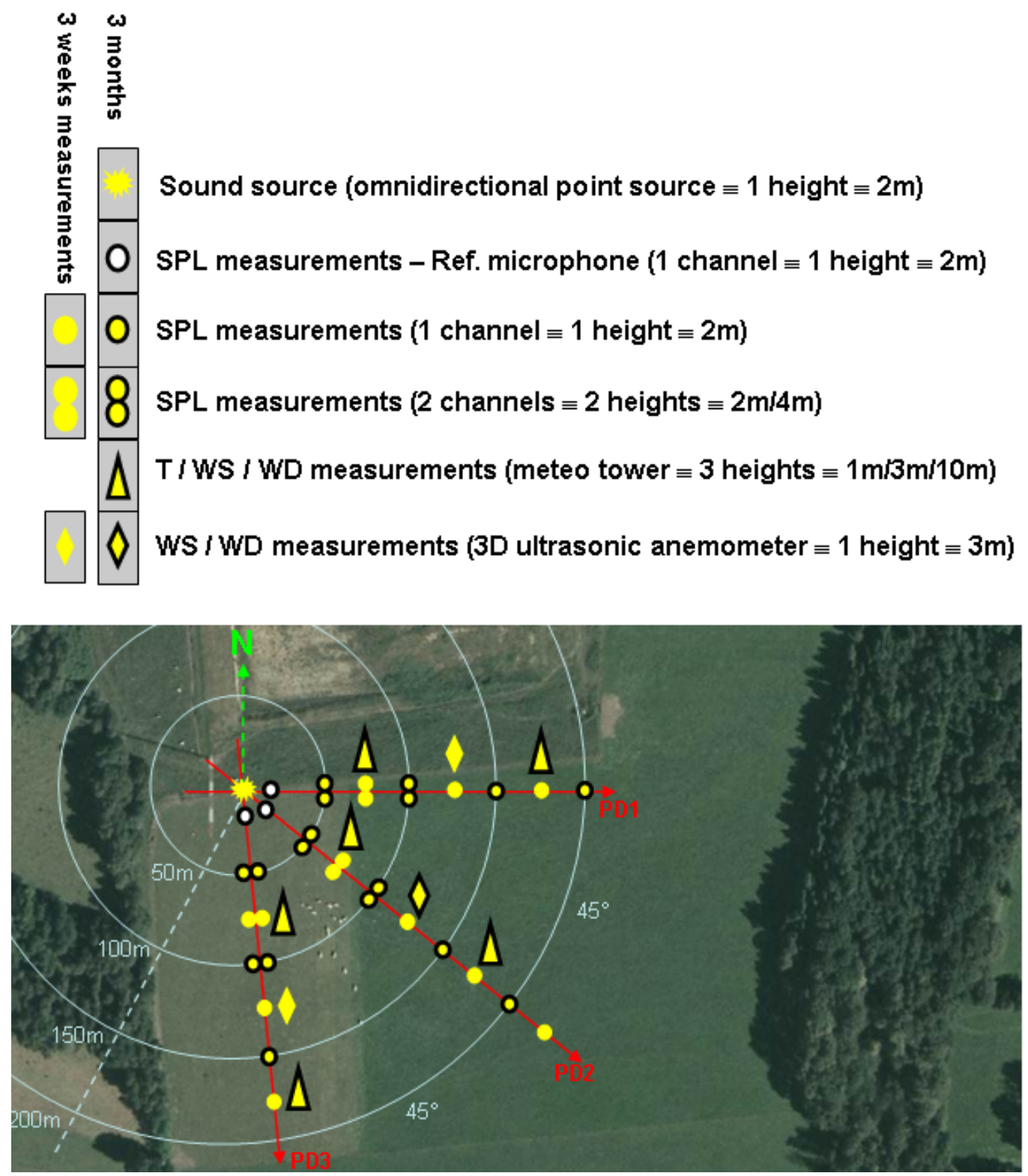

Figure 1: Lannemezan-2005 experiment, acoustical and meteorological sensor locations. 
The 3 days chosen were:

- 17th June 2005 during day-time, corresponding to unstable conditions $(\zeta=-0.3)$, unfavorable propagation conditions along the PD1 direction and homogeneous conditions along PD3;

- 3rd July 2005 during night-time, corresponding to very stable conditions $(\zeta=0.3)$ and favorable propagation conditions along PD3 ;

- 16th June 2005 during night-time, presenting neutral-stable atmospheric characteristics $(\zeta=0.1)$ and favorable propagation conditions along the PD1 and PD3 directions.

\section{Meso-NH}

\subsection{Presentation}

Meso-NH is the non-hydrostatic meso-scale atmospheric model produced by the French research community [3]. It is intended to be applicable at all atmospheric scales, ranging from large (synoptic) scales to small scales (Large-Eddy Simulation). The model can use a 3D 1.5 order turbulence scheme, with two different mixing length parameterizations $[4,5,6]$. Its performance for several boundary layer regimes has been tested successfully $[7,8,9]$. The model allows for all types of boundary layers (stable, neutral, unstable) to be investigated over different types of surface cover and provides a resolution on the order of $1 \mathrm{~m}$. However, for such high resolutions, a description of the effects of the canopy on flow using a roughness approach (as is usually done in large-scale atmospheric models) was not sufficient. Thus, a new development has been introduced in order to take into account 
the drag force of the high vegetation[10]. A detailed description of the basic equations of the Meso-NH model is available into the Meso-NH scientific manual [11].

\subsection{Configuration}

Simulations were conducted using 3 grid-nested domains centered on the main domain of the Lannemezan-2005 site. The domain size was chosen large enough to resolve the large-scale eddies. Large-eddy simulations (LES) are performed with horizontal resolutions of $50 \mathrm{~m}, 10 \mathrm{~m}$ and down to $2 \mathrm{~m}$ in order to resolve the smallest eddies. A vertical terrain-following stretched grid is used with 50 levels in the first $100 \mathrm{~m}$ above ground, for a total of 80 levels up to $6000 \mathrm{~m}$. Table 1 summarizes the model configurations. It can be noticed that for the unstable case (17-06-2005), the vortices are large enough to make the third model unnecessary. Surface fluxes were output by the surface model ISBA [12]. The cover positioning was derived from interpolation of the Corine database [13] (horizontal resolution of $250 \mathrm{~m}$ ) except for the field experiment of Lannemezan-2005 where the data have been completed manually in order to better describe the position of trees. As an initialization for the Meso-NH simulations, vertical wind and temperature profiles have been assumed using ARPEGE analysis [14] above $60 \mathrm{~m}$ and observations of the $60 \mathrm{~m}$ tower below. Then, this profile is interpolated vertically and horizontally over the whole domain, taking into account the orography. 
Table 1: Configuration of the nested models - DEAR: Deardorff mixing length, BL89: Bougeault Lacarrere mixing length [2].

\begin{tabular}{|c|c|c|c|}
\hline $\begin{array}{l}\text { Horizontal } \\
\text { Resolution }\end{array}$ & \multirow[t]{2}{*}{ 1st Grid } & \multirow[t]{2}{*}{ 2nd Grid } & \multirow[t]{2}{*}{ 3rd Grid } \\
\hline $\begin{array}{l}\text { Mixing } \\
\text { length }\end{array}$ & & & \\
\hline \multirow{2}{*}{$\begin{array}{c}\text { 03-07-2005 } \\
\text { 04h30 } \\
\text { Stable }\end{array}$} & $50 \mathrm{~m}\left(10 \times 10 \mathrm{~km}^{2}\right)$ & $10 \mathrm{~m}\left(2 \times 2 \mathrm{~km}^{2}\right)$ & $3.3 \mathrm{~m}\left(500 \times 400 \mathrm{~m}^{2}\right)$ \\
\hline & BL89 & BL89 & DEAR \\
\hline \multirow{2}{*}{$\begin{array}{c}\text { 16-06-2005 } \\
\text { 04h30 } \\
\text { Neutral }\end{array}$} & $50 \mathrm{~m}\left(10 \times 10 \mathrm{~km}^{2}\right)$ & $10 \mathrm{~m}\left(2 \times 2 \mathrm{~km}^{2}\right)$ & $3.3 \mathrm{~m}\left(500 \times 400 \mathrm{~m}^{2}\right)$ \\
\hline & BL89 & BL89 & DEAR \\
\hline \multirow{2}{*}{$\begin{array}{c}\text { 17-06-2005 } \\
\text { 16h00 } \\
\text { Unstable }\end{array}$} & $50 \mathrm{~m}\left(10 \times 10 \mathrm{~km}^{2}\right)$ & $10 \mathrm{~m}\left(2 \times 2 \mathrm{~km}^{2}\right)$ & $\mathrm{X}$ \\
\hline & DEAR & DEAR & $\mathrm{X}$ \\
\hline
\end{tabular}




\subsection{Results}

Figs. 2, 3 and 4 show the comparison between simulation and experimental results for the profiles of wind speed, temperature and turbulent kinetic energy (TKE) at the three selected times (local time). The mean vertical profile is calculated from a space and time averaging over the different masts (on PD1, PD2 and PD3), and over 15 min time periods. In this particular case of the 16th of June 2005 at 04 h30 (Fig. 2), we observe good agreement between experimental results and Meso-NH simulations. Let's note in par-

ticular the good reproduction of the inflection point in the wind speed and the very good representation of the TKE mean vertical profile. For the neutral and unstable cases (06-17-2005, Fig. 2 and 06-16-2005, Fig. 3), there is a good agreement between Meso-NH simulations and experimental results. For the stable case (07-03-2005, Fig. 4), Meso-NH simulations produce an excessive wind speed value. Regarding temperature and TKE values, a more detailed review has been presented in [15]. Finally, Meso-NH is considered as a relevant model to provide input data for propagation simulations with the TLM method.

\section{TLM}

As described in the associated paper (Part 1), recent developments of the TLM method have been carried out and validated in order to take into account different ground impedance characteristics [16], fully-absorbing boundary layers [17] and meteorology [18]. Thus, the TLM can now be considered as a reference method for the simulation of outdoor sound propagation. 

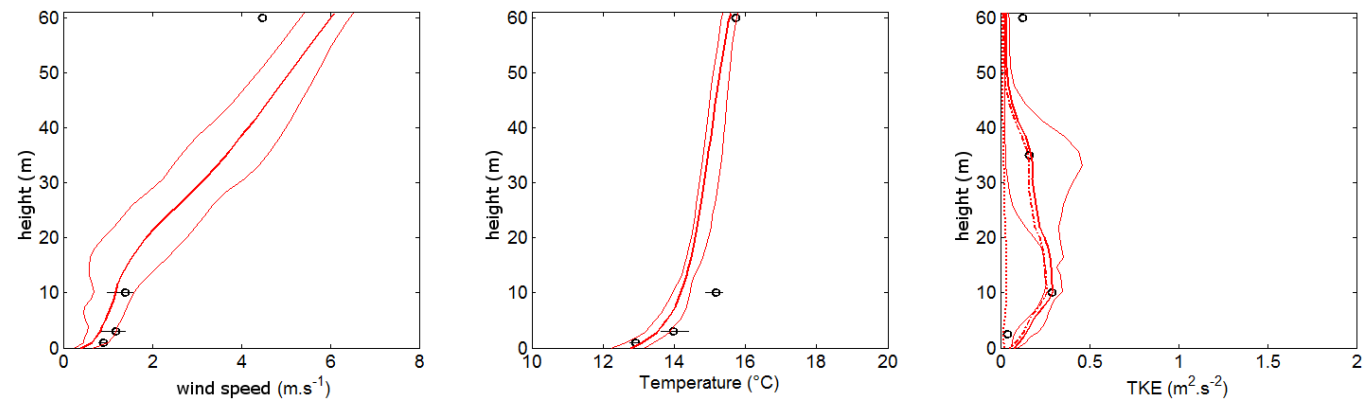

Figure 2: Mean vertical profiles (thick line) and dispersion (thin lines) of the wind speed, temperature and turbulent kinetic energy (total TKE in continuous line with dispersion, subgrid TKE in dashed line and resolved TKE in dotted line), both measured (black) and simulated (red) on 16-06-2005 at 04h30 (neutral case).
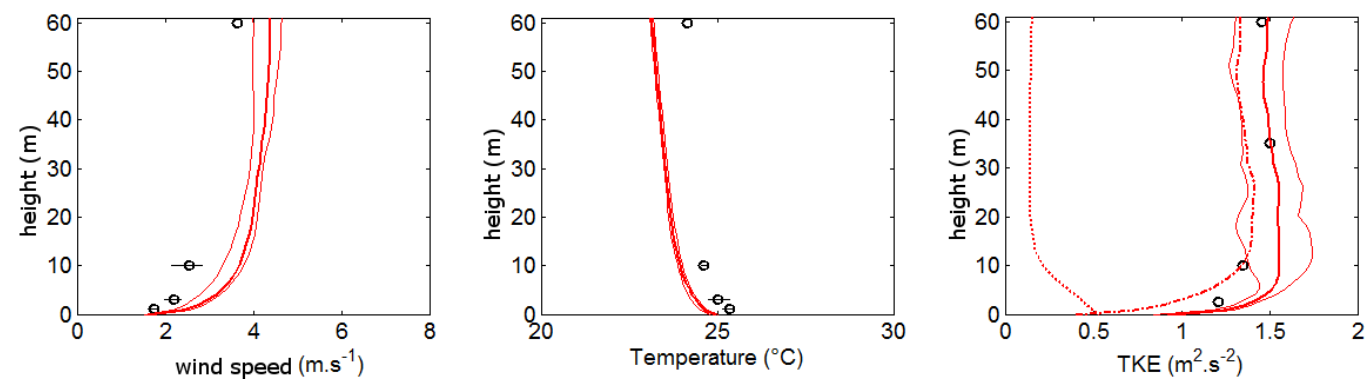

Figure 3: Mean vertical profiles (thick line) and dispersion (thin lines) of the wind speed, temperature and turbulent kinetic energy (total TKE in continuous line with dispersion, subgrid TKE in dashed line and resolved TKE in dotted line), both measured (black) and simulated (red) on 17-06-2005 at 16h30 (unstable case). 

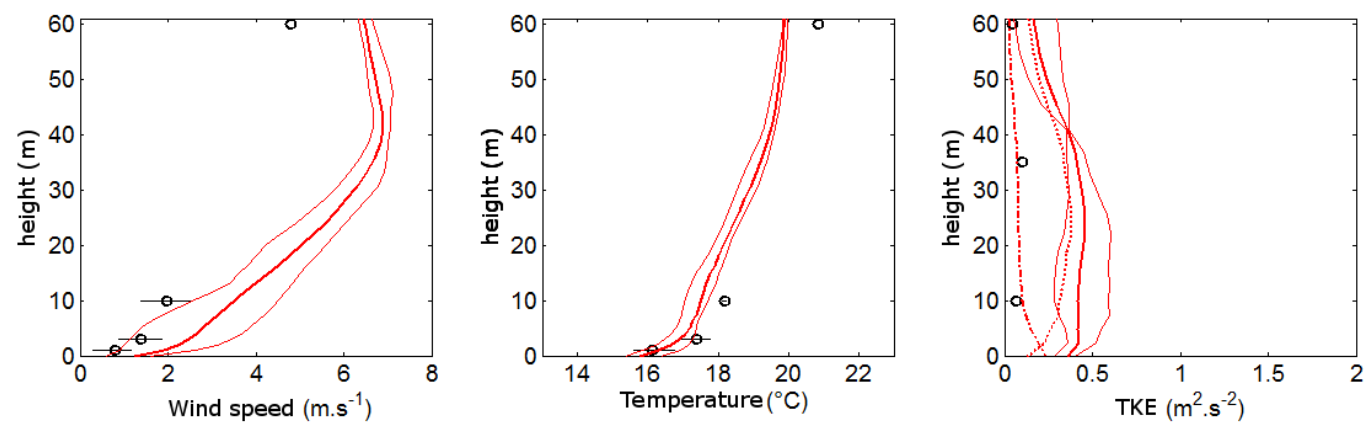

Figure 4: Mean vertical profiles (thick line) and dispersion (thin lines) of the wind speed, temperature and turbulent kinetic energy (total TKE in continuous line with dispersion, subgrid TKE in dashed line and resolved TKE in dotted line), both measured (black) and simulated (red) on 03-07-2005 at 04h30 (stable case).

\subsection{Configuration}

For the following simulations, the spatial resolution of the TLM method is $0.04 \mathrm{~m}$ and performed in $2 \mathrm{D}$ during 0.65 seconds. The central frequency of the sound source (gaussian pulse) is $500 \mathrm{~Hz}$. Perfectly absorbing boundary layers are set around the computational domain, except on the bottom side where ground impedance conditions are assumed to be absorbing. In the Miki impedance model [16], air flow resistivity is set at 150 k.N.s.m ${ }^{-4}$, which is the measured mean value during the Lannemezan-2005 experiment [19]. The meteorological fields (temperature and wind) are extracted on each propagation direction and integrated into the acoustic model. Because of the major difference in time scales between acoustical and meteorological fluctuations (e.g. sound speed $\sim 340 \mathrm{~m} \cdot \mathrm{s}^{-1}$ vs air flow speed $\sim 10 \mathrm{~m} \cdot \mathrm{s}^{-1}$ ), it has been decided to use fixed meteorological variables during the time duration of the simulation $(0.65 \mathrm{sec})$. 


\subsection{Results}

In this paper, only $315 \mathrm{~Hz}, 400 \mathrm{~Hz}, 630 \mathrm{~Hz}$ and $800 \mathrm{~Hz}$ third octave band results are presented for the different cases in the PD3 propagation direction. It is possible to find exhaustive results in [15]. In order to compare TLM simulations with measurements under very weak meteorological effects, near perfect homogeneous conditions (vertical speed sound gradient $<0.015 \mathrm{~s}^{-1}$ ) have first been extracted from the Lannemezan-2005 database. This comparison is reported in grey on the figures 5, 6 and 7, which shows a very good agreement between simulated and measured values at any distances and for all frequency bands. This confirms that the choice of ground impedance parameters is sufficiently accurate and relevant [14, 20, 21]. TLM simulations using vertical linear profiles are also proposed, in red on the figures. The gradient is calculated at a height of $3 \mathrm{~m}$ from the measurements, which allows validating the accuracy of the TLM method and better evaluating the impact of the input meteorological data. 

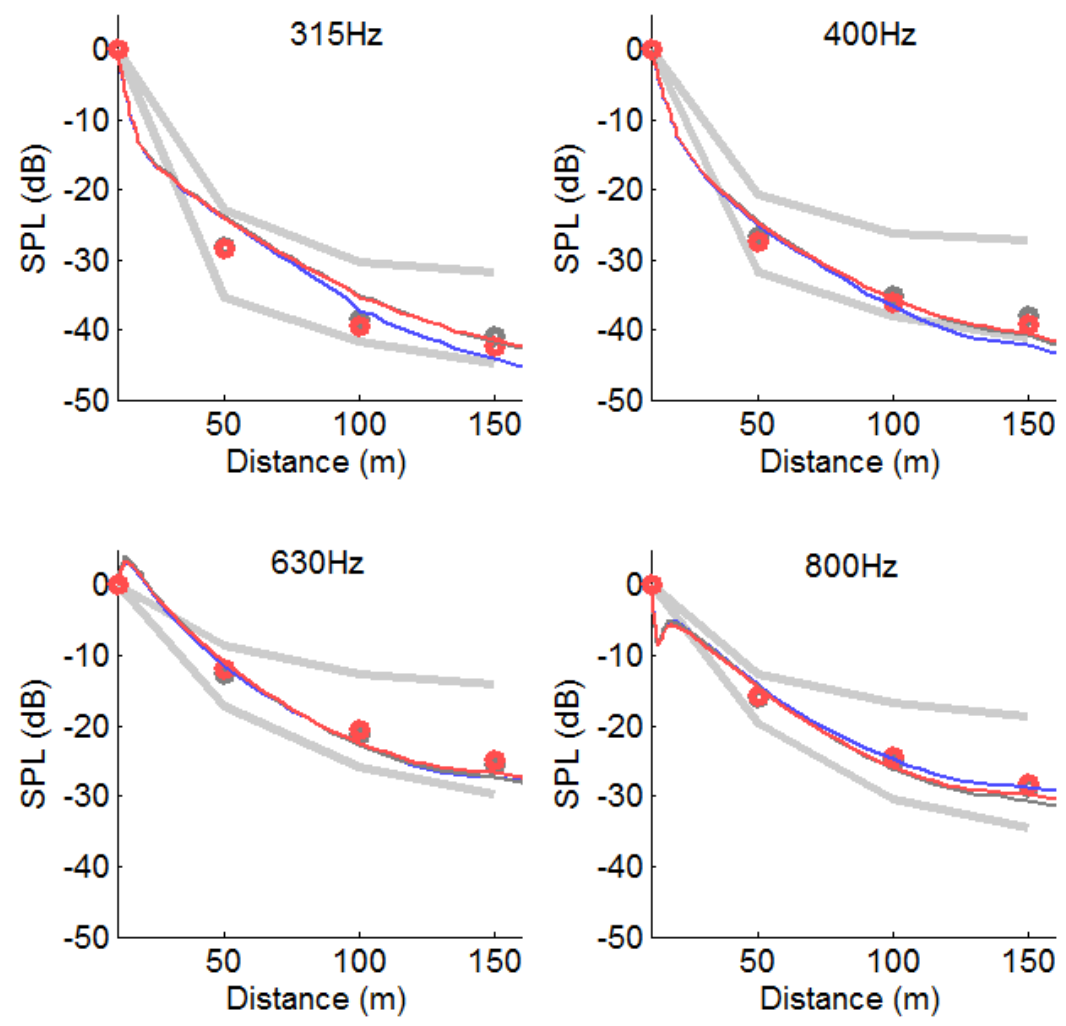

Figure 5: Sound attenuation (normalised by the free field and by a reference microphone located $10 \mathrm{~m}$ from the sound source) as a function of the distance from the source, for $315 \mathrm{~Hz}, 400 \mathrm{~Hz}, 630 \mathrm{~Hz}$ and $800 \mathrm{~Hz}$ third octave bands. The bold grey lines traduce the experimental dispersion over the three-month measurements. Comparison between experimental data during the campaign of Lannemezan 2005 (points) and TLM predictions (full line) using (blue) measured meteorological conditions on 17-06-2005 at $16 \mathrm{~h} 30$ following PD3, (grey) nearly-homogeneous conditions and (red) rough (linear) vertical profiles of sound speed. 

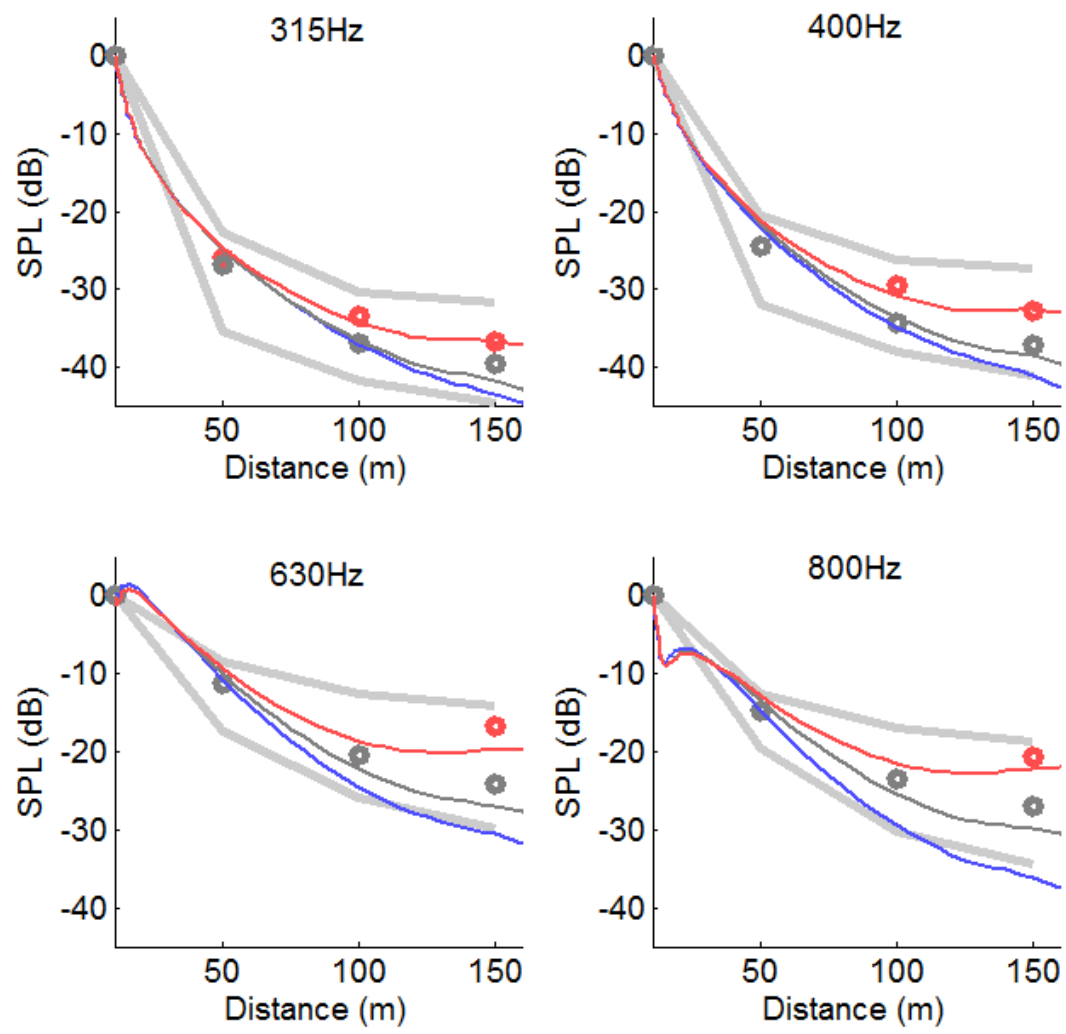

Figure 6: Sound attenuation (normalised by the free field and by a reference microphone located $10 \mathrm{~m}$ from the sound source) as a function of the distance from the source, for $315 \mathrm{~Hz}, 400 \mathrm{~Hz}, 630 \mathrm{~Hz}$ and $800 \mathrm{~Hz}$ third octave bands. The bold grey lines traduce the experimental dispersion over the three-month measurements. Comparison between experimental data during the campaign of Lannemezan 2005 (points) and TLM predictions (full line) using (blue) measured meteorological conditions on 03-07-2005 at 04h30 following PD3, (grey) nearly-homogeneous conditions and (red) rough (linear) vertical profiles of sound speed. 

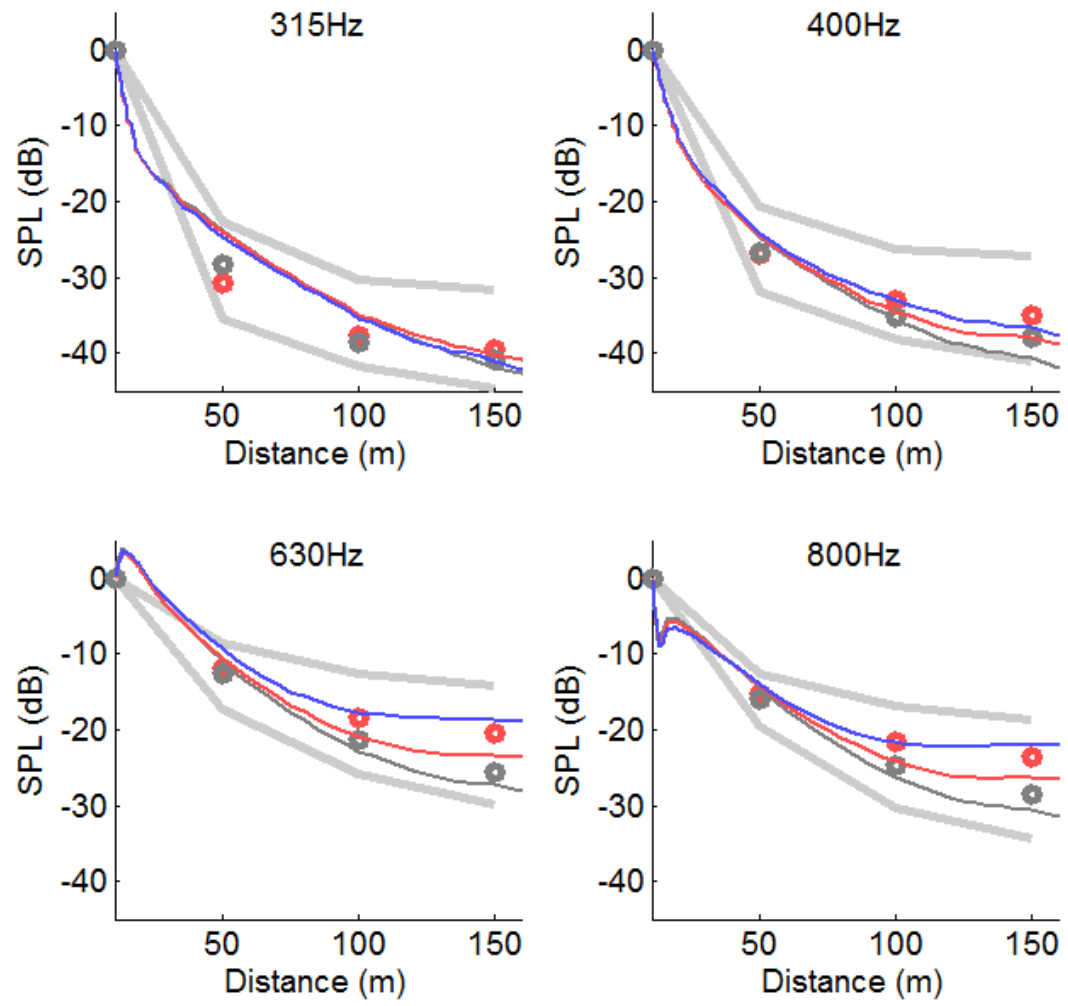

Figure 7: Sound attenuation (normalised by the free field and by a reference microphone located $10 \mathrm{~m}$ from the sound source) as a function of the distance from the source, for $315 \mathrm{~Hz}, 400 \mathrm{~Hz}, 630 \mathrm{~Hz}$ and $800 \mathrm{~Hz}$ third octave bands. The bold grey lines traduce the experimental dispersion over the three-month measurements. Comparison between experimental data during the campaign of Lannemezan 2005 (points) and TLM predictions (full line) using (blue) measured meteorological conditions on 16-06-2005 at 04h30 following PD3, (grey) nearly-homogeneous conditions and (red) rough (linear) vertical profiles of sound speed. 
Then, the meteorological variables (wind and temperature) of the TLM model are derived from Meso-NH simulation results on the same site and for the same dates. These comparisons between TLM simulations and experimental data are presented in red in Fig. 5 (blue line for "exact" profiles directly generated from Meso-NH). These comparison results generally show very good agreement and especially underscore the benefit in taking into account meteorological effects during acoustic propagation, even with only roughly fitted (linear) meteorological profiles. The different case studies have shown that:

- For unstable case (Fig. 5), a good accuracy of the TLM method under relatively homogeneous conditions. This confirms that the choice of ground impedance parameters is sufficiently accurate and relevant and moreover that TLM is suitable for the purpose of outdoor sound propagation.

- In stable conditions (Fig. 6), because the sound pressure levels are very sensitive to the meteorological fields and, in the case of low quality Meso-NH simulations, the TLM simulations can be sometimes quite far from experiments. When using vertical profiles calculated from measurements, the TLM simulations show significantly better results.

- For neutral case (Fig. 7), if the atmospheric boundary layer simulated by Meso-NH is in sufficient agreement with the meteorological observations, then the TLM sound predictions are also in good agreement with the corresponding experimental acoustic data.

Finally, these comparative results generally show a good agreement, even 
with only roughly fitted (linear) meteorological profiles.

\section{Conclusion}

This paper deals with the use of the meso-scale meteorological model (Meso-NH) in order to enhance the time-domain sound propagation model (TLM) with temperature and wind speed profiles. Thanks to the comparison between simulation results and experimental data derived from the Lannemezan-2005 campaign, this study has shown the strong sensitivity of the acoustical model to the vertical profiles of temperature and wind speed, and has thus demonstrated the need to make use of accurate meteorological simulations as input data. The associated paper (Part 1) having shown the relevance of the TLM method for outdoor acoustic propagation modeling, the present Part 2 has raised the interest of this prospective work from the perspective of coupling acoustical and meteorological models.

\section{References}

[1] F. Junker, B. Gauvreau, D. Ecotière, C. Cremezi-Charlet, Blanc-Benon, Meteorological classification for environmental acoustics-practical implications due to experimental accuracy and uncertainty, in: International Congress on Acoustics (ICA), Vol. 38, Madrid, Spain, 2007.

[2] T. Foken, Micrometeorology, Springer Verlag, 2008.

[3] J. Lafore, J. Stein, N. Asencio, P. Bougeault, V. Ducrocq, J. Duron, C. Fischer, P. Hereil, P. Mascart, J. Pinty, J. Redelsperger, E. Richard, J. V. d. Arellano, The Meso-nH atmospheric simulation system. Part I: 
Adiabatic formulation and control simulations, Annales Geophysicae 16 (1998) 90-109.

[4] J. W. Deardorff, Stratocumulus-capped mixed layers derived from a three-dimensional model, Boundary-Layer Meteorology 18 (4) (1980) $495-527$.

[5] J. Cuxart, P. Bougeault, J. Redelsperger, A turbulence scheme allowing for mesoscale and large-eddy simulations, Quarterly Journal of the Royal Meteorological Society 126 (2000) 1-30.

[6] P. Bougeault, P. Lacarrere, Parameterization of Orography-Induced turbulence in a MesobetaScale model, Monthly Weather Review 117 (1989) 1872-1890.

[7] J. Cuxart, C. Yague, G. Morales, E. Terradellas, J. Orbe, J. Calvo, A. Fernndez, M. R. Soler, C. Infante, P. Buenestado, et al., Stable atmospheric boundary-layer experiment in Spain (SABLES 98): A report, Boundary-Layer Meteorology 96 (3) (2000) 337370.

[8] M. A. Jiménez, J. Cuxart, Large-eddy simulations of the stable boundary layer using the standard Kolmogorov theory: Range of applicability, Boundary-Layer Meteorology 115 (2) (2005) 241-261.

[9] S. Tomas, V. Masson, A parameterization of third-order moments for the dry convective boundary layer, Boundary-Layer Meteorology 120 (3) (2006) 437-454. 
[10] P. Aumond, C. Lac, V. Masson, B. Gauvreau, M. Bérengier, Including drag effects of canopies: Real case large-eddy simulation studies, Boundary Layer Meteorology 146 (1) (2013) 65-80.

[11] The MesoNH atmospheric simulation system : scientific documentation, CNRS, Météo France, 2009.

[12] J. Noilhan, J. Mahfouf, The ISBA land surface parameterisation scheme, Global and Planetary Change 13 (1-4) (1996) 145-159. doi:10.1016/0921-8181(95)00043-7.

URL http://www.sciencedirect.com/science/article/pii/0921818195000437

[13] M. Bossard, J. Feranec, J. Otahel, CORINE land cover technical guide: addendum 2000, European Environment Agency Copenhagen, 2000.

[14] M. Déqué, C. Dreveton, A. Braun, D. Cariolle, The ARPEGE/IFS atmosphere model: A contribution to the French community climate modelling, Climate Dynamics 10 (1994) 249-270.

[15] P. Aumond, Modélisation numérique pour l'acoustique environnementale : simulation de champs météorologiques et intégration dans un modèle de propagation, Ph.D. thesis, Université du Maine (2011).

[16] G. Guillaume, J. Picaut, G. Dutilleux, B. Gauvreau, Time-domain impedance formulation for transmission line matrix modelling of outdoor sound propagation, Journal of Sound and Vibration 330 (26) (2011) 6467-6481. doi:10.1016/j.jsv.2011.08.004.

[17] G. Guillaume, J. Picaut, A simple absorbing layer implementation for 
transmission line matrix modeling, Journal of Sound and Vibration 332 (19) (2013) 4560-4571. doi:10.1016/j.jsv.2013.04.003.

[18] G. Dutilleux, Applicability of TLM to wind turbine noise prediction, in: Second International Meeting on Wind Turbine Noise, Lyon, France, 2007.

[19] O. Baume, B. Gauvreau, M. Bérengier, F. Junker, H. Wackernagel, J. Chilès, Geostatistical modeling of sound propagation: Principles and a field application experiment, The Journal of the Acoustical Society of America 126 (2009) 2894-2904. doi:10.1121/1.3243301.

[20] D. De Cogan, W. J. O'Connor, S. Pulko, Transmission Line Matrix in Computational Mechanics, CRC Press, ISBN 978-0-415-32717-6, London, England, 2005.

[21] P. Aumond, G. Guillaume, B. Gauvreau, C. Lac, V. Masson, M. Bérengier, Coupling time domain acoustical and mesoscale meteorological models, in: 14th Long Range Sound Propagation Symposium (invited paper), Annapolis (USA), 2011. 